\title{
Integration of Macro and Micro Sustainability Issues: The Need for 'Engineering Accounting'
}

\author{
Joanne L. Tingey-Holyoak, Roger L. Burritt, and John D. Pisaniello \\ Centre for Accounting, Governance and Sustainability \\ University of South Australia, Adelaide, South Australia 5000, Australia \\ \{joanne.tingey, roger.burritt, john.pisaniello\}@unisa.edu.au
}

\begin{abstract}
The paper argues for the integration of engineering and accounting professionals through a transdisciplinary approach to on-farm water issues associated with farm dams. An integrated macro and micro solution is put forward in the context of poor farmer behaviour as spillways are blocked to pursue individual aims at the expense of other stakeholders, including downstream communities and the environment. Integrated engineering accounting is proposed as a solution through transdisciplinary thinking.
\end{abstract}

Keywords: integrated engineering accounting, transdisciplinarity, farm dams, spillway blocking.

\section{Introduction}

As accountancy professional bodies worldwide move to calls to expand the boundaries of the accounting discipline to incorporate environmental sustainability measures, there is evidence to suggest that there has been difficulty in integrating aspects of the environment into practice [8]. In the main this is because of the intricacies of the engineering aspects involved in accounting for elements of the environment. Ngwakee [8] suggests, in the context of sustainable development, accounting and engineering are like uncongenial twins (see earlier analogy between accounting and economics [2]) and should be recognised through the notion of 'engineering accounting'. Engineering accounting is portrayed to be a specialized field of accounting designed to handle the complex technical and socio-political accounting problems that climate change and carbon trading present, and which brings together macro (economy wide) and micro (company based) notions of accounting [21]. But this narrow setting is generalizable to all settings where engineering and accounting contribute to a transdisciplinary solution.

Accounting for carbon, water, biodiversity, electricity usage and other environmental sustainability measures all require engineering knowledge and without this, the accounting profession's involvement in the critical organisation-environment boundary is limited. Despite acknowledgement of the transdisciplinary nature of sustainability accounting, it is apparent that continuous reliance on engineers reduces the power of accountants to evolve in line with the changing demands of macro and micro stakeholders such as society, international agencies, clients of firms and professional bodies. 
'Engineering accounting' would embody all of the aspects of any recognised profession, education and training for technical proficiency, independence of perspective, support for public interest as well as recognition of the importance of member needs and a system to measure, evaluate, record, interpret and report organizational sustainability information but not just for audit purposes as suggested by Ngwakwe [8]. The purpose is much broader and can be mainstreamed in traditional and environmental accounting practices providing sustainability information to all types of managers production, product, divisional, marketing, environmental and top management [3]. The accounting and engineering professions face an opportunity to capture their presently unrecognised relevance in a joint initiative mainstreaming an integrated set of sustainable development activities common to the currently separate, siloed professions - accounting and engineering.

The behaviours of actors over water, a critical environmental aspect of sustainability and the suggested future of global tensions to rival those over oil [9] can be accounted for by a combination of engineering and accounting expertise and is considered here to illustrate the way in which 'engineering accounting' can help to understand the reasons for and the behaviours of, for example, farmers desperate to secure water for their farming activities. Engineering accountants would stand together as joint participants in the engineering and accounting professions. The code of ethics for professional accountants APES110 prescribes that accountants safeguard against threats to their ability to perform duties with the appropriate degree of professional competence by consulting with independent experts or obtaining additional training themselves [1]. This was evidenced with the recent release of the first Australian Water Accounting Standard [19] which raises interesting issues of the reliance on experts, specifically engineers, to provide the numbers to be used by accountants. The development of and training for 'engineering accounting' would reduce this reliance thereby creating specialised accountants equipped to measure, record and interpret organisational environmental sustainability information. Such accountants would be educated at the tertiary level and by the professional firms through specially designed university courses and professional development as well as certification designed to recognise skills acquired.

The paper addresses the bringing together of a team of accountants and engineers to study the possibility of specialised engineering accounting for one of the world's largest surface fresh water resources, farm dams. The research problem being addressed is how macro and micro sustainability solutions can be encouraged through engineering accounting using the example of the urgent need for solutions to the risks from inequitable water sharing and safety threats.

\section{Accounting for Sustainability - Farm Dams}

It is critically important to measure and account for fresh water resources, especially in areas with increasing frequency of not only droughts but also flash flooding [4], [18]. Not accounting for fresh water resources has far reaching consequences at the micro level for businesses and industries, and increasingly at the macro level for society, the economy and aquatic and land ecosystems [10]. For agriculture, dams are the 

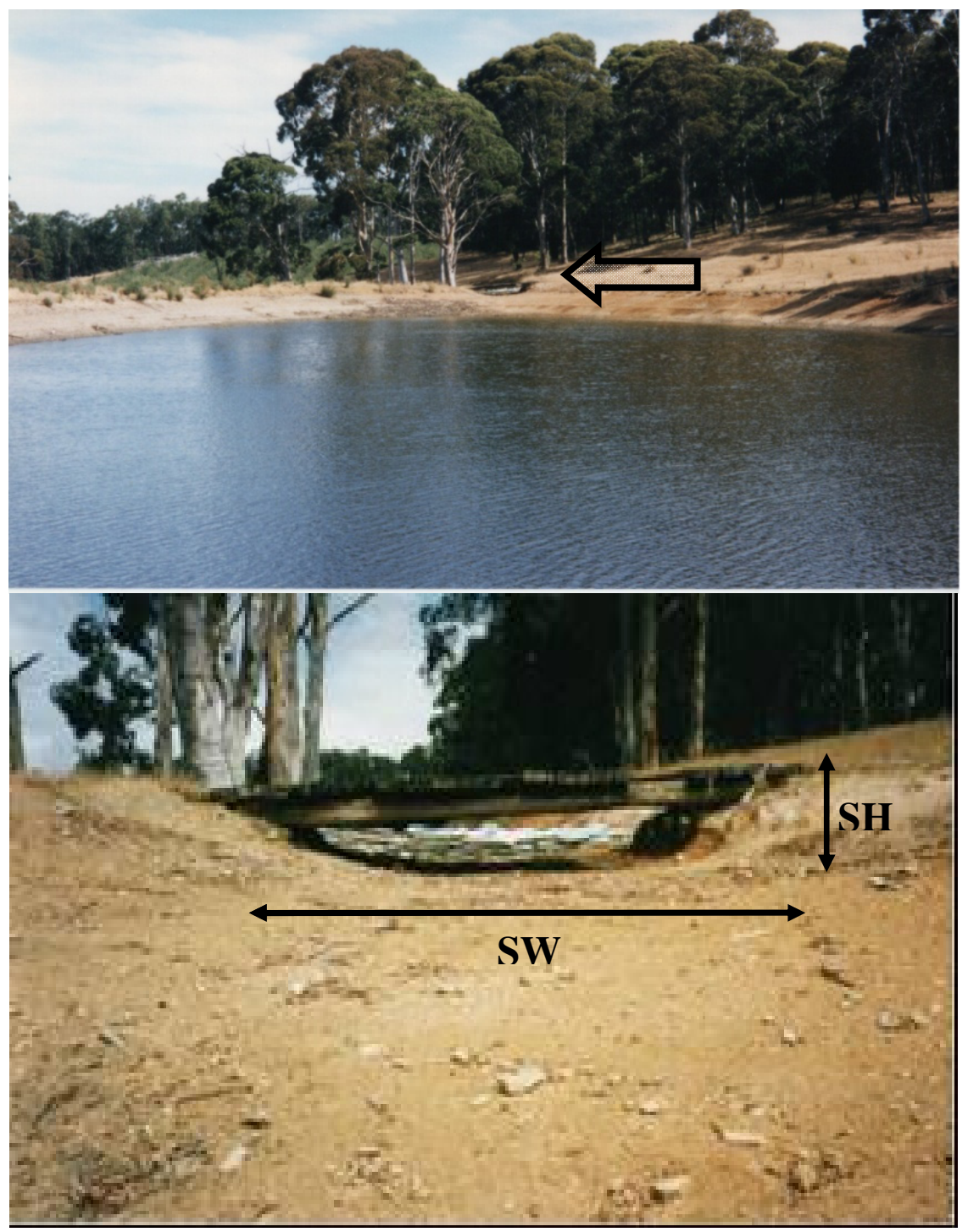

Fig. 1. An under-designed spillway ${ }^{1}$. SH = Max. Spillway Height, $\mathrm{SW}=$ Max. Spillway Width

${ }^{1}$ The spillway (located in South Australia) size is clearly too small for this 100 ML impoundment. The spillway is also badly maintained as the owner allows physical obstructions, including a walkway bridge and sandbags, to be present across the spillway restricting its potential capacity. Cost-effective spillway safety technology enables the existing dimensions of the spillway (i.e. Spillway Height, SH and Width, SW) to be reviewed for adequacy by 'non engineers' due to its simplicity. It can also be used in design mode to readily determine what spillway size is needed (i.e. by how much SH and/or SW must be increased) to ensure adequate flood safety for the dam whilst being able to accommodate both the farmer's minimum storage capacity requirements and the lowest cost earthworks. At the same time the technology is in line with modern engineering best practice [13]. 
"lifeblood" of most farming businesses as they provide stocks of essential water supply for irrigation and other farming activities. However, a problem exists with a lack of accounting for farm dams and their safety in that thousands of dam structures have failed and many more pose significant safety threats [11-14]. In China the Shimantan and Banquia dams failed in 1975 because of the cumulative failure of 60 smaller upstream dams, resulting in the deaths of 230,000 people [20]; in the United States, the 5m Evans and Lockwood dams, which held only 89ML and 39ML of water respectively, both collapsed in a cascade manner in 1989, devastating communities and killing 2 people [5]; and, in Quang Binh Province, Vietnam in 2010, 85,000 homes and businesses were flooded and at least 16 people died after water rose more than one metre over a large public dam following heavy flooding in the catchment which contained many small dams [16]. Dam failure for a farming business can mean: no longer being able to water valuable crops, the subsequent loss of those crops, serious inconvenience to farming activities, substantial cost to repair or replace the dam, and possible liability for downstream consequences [7], [14].

Furthermore in times of drought, farmers have an incentive to store water using inequitable and unsustainable tactics such as the blocking of spillways (see Figure 1) [14]. Thus, whilst farm dams can reduce farming risks associated with water shortages, during periods of low rainfall in the catchment, they also reduce water available for downstream users and the environment [15], especially when unfairly managed in this way. Hence, management of a farm dam to maintain its performance, structural integrity and safety are vital for the sustainability of farming business [14]. But, accounting for the structure and its stocks and flows is also important for the safety and sustainability of the downstream community and environment.

Unfortunately, many countries and regions do not have an integrated water accounting system for dams [14] that can effectively capture the linkages and interactions within or between macro and micro economic production and consumption, fresh water resource depletion and socio- and hydro-ecosystem degradation [6]. By bringing together engineers and accountants the research is finding that sustainability accounting provides a tool for identifying and making transparent the costs to business, the community and policy-makers associated with dam failure and inequitable water sharing.

\section{Accounting Issues}

Lessons from the past indicate that key issue for accounting for sustainable farm dams is the institutionally fragmented nature of actors who are operating, managing, regulating and overseeing the accounting for sustainable dam management [25] (Figure 2). These actors are often pursuing individual management goals because of sub-optimal local decision making rather than global optimal decisions for flood risks to communities in any catchment [22]. Changing climate conditions and forecasts of increases in extreme weather events mean that the narrow focus of actors will only increase [26]. However, before moves can be made to overcome institutionally divided approaches, a clear understanding of the accounting issues for sustainable farm dam management is required. 


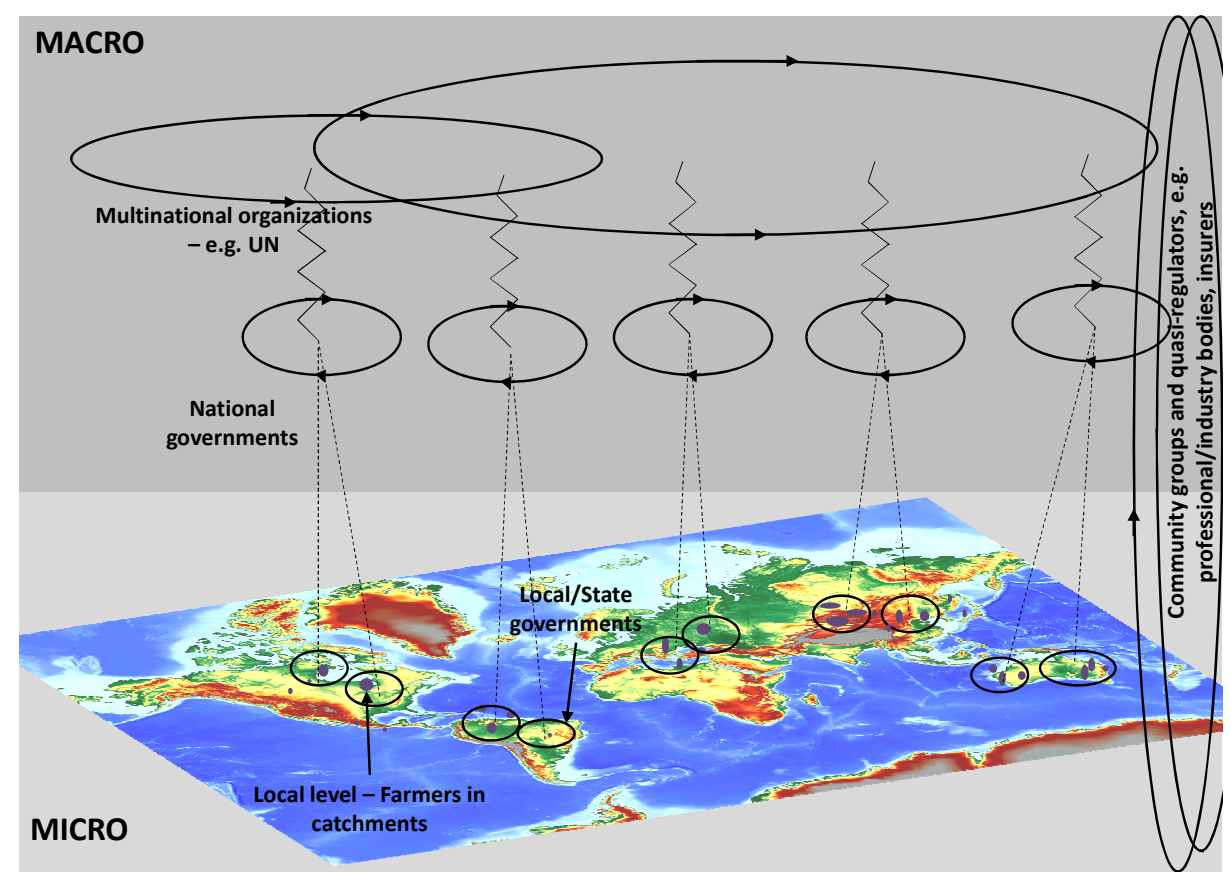

Fig. 2. Fragmented nature of institutional actors involved in accounting for sustainable farm dams

\subsection{Micro Accounting Issues}

\section{Engineering Accounting for Direct, Indirect and Hidden Costs}

The cost of sustainable farm dam management includes conventional direct and indirect costs such as equipment for maintaining a dam, or monitoring equipment to measure dam capacity. However there are also four types of costs which potentially remain hidden because neither engineering nor accounting systems separately identify them. Upfront costs are incurred prior to the operation of a dam and include costs related to the choice of site, site preparation, permits, engineering and installation. Regulatory costs of dam operations involve notification, reporting, monitoring and testing, modelling studies, remediation, planning, training, inspections, insurance, assurance or audit, pollution control, spill or failure response, taxes and fees. There are also voluntary costs of operations linked with community outreach and stakeholder engagement, monitoring and testing, training, assurance, reporting, insurance, recycling, habitat protection, landscaping, and financial support to nongovernment organisations. Back end costs relate to site survey, the decommissioning of dams, and post-closure care.

\section{Contingent Liabilities}

There are also non-certain contingent costs that can be associated with probabilistic calculations (expected value, variance, etc.). These contingent liabilities include the costs of remedying and compensating for dam failure and related fines and penalties 
for non-compliance, remediation for property damage or damage to natural resources, personal injury, legal expenses, relationships with downstream communities and relationships with regulators.

\subsection{Macro Accounting Issues}

\section{Social and Environmental Costs}

Image and relationship costs associated with dam management are tangible but the benefits that result from trying to affect the perceptions of different stakeholders such as downstream communities, non-government organisations and regulators are intangible. Reporting and assurance costs provide one example, community relations activities another, and costs of downstream protection activities such as developing an emergency action plan or tree planting a third. However, environmental costs are mostly ignored, with all but the most basic costs being brought to light because of the limited ability of accountants to undertake 'engineering accounting'.

\subsection{State of the Art in Engineering Accounting for Sustainable Water Storage}

Accounting for sustainable farm dam management can be possible, when complemented by the appropriate institutional response [25]. The technological engineering accounting tool developed by [13] based on best practice catchment analysis, calibration and modelling, flood hydrology and reservoir hydraulics, all in line with [23] provides an example of a possible mechanism to create a sustainability account of farm dams in a region. The accounting tool allows for measurement of the hydraulic response of any size of reservoir and spillway(s) relative to the hydrological flood response of the selected rural catchment in an 'hydrologically homogenous' region for the full range of design storm events up to the Probable Maximum Precipitation (i.e. 1 in 10,000,000 years Annual Exceedence Probability (AEP)). This accounting tool has been developed in South Australia, Victoria and New South Wales [24] in order to promote consistency and uniform standards in the sustainability of farm dams and practical application involves using a regionalised relationship based on simple hydrological/hydraulic variables, for predicting reservoir flood capability - known as Dam Crest Flood (DCF) (see [13]) and is cost-effective and simple to use. The tool would enable diverse actors to access reliable measures for monitoring and overseeing the sustainability of farm dams in a region.

\section{Conclusion}

This paper addresses the bringing together of a team of accountants and engineers to study the possibility of specialised engineering accounting for one of the world's largest surface fresh water resources, farm dams. By addressing the research problem of how macro and micro sustainability solutions can be encouraged through engineering accounting, the paper draws awareness to the challenge for researchers and professionals to traverse and span multiple disciplines for sustainability solutions, especially when faced with ever increasing weather related disasters. However, what is also highlighted is the need for an urgent future research agenda that includes gathering evidence from 
key macro and micro stakeholders through government, community and professional body perception, attitude and behaviour surveys.

Perhaps this is a timely opportunity to draw from the lessons of the past, such as those experienced by the accounting profession when faced with the challenge of fraud, who developed the specialised forensic accounting stream, or other professions coping with changes in the environment such as economists who created the ecological economics concentration. In addition, public and investor confidence in the amount of water traded, consumed, recovered and managed for environmental and other public benefit outcomes will be improved in conjunction with understanding of how fresh water resources are sourced, managed, shared and used. Importantly, new opportunities are presented: for the marketing of transdisciplinary professional services, for professional development, for educators of professional services graduates, for water resource managers and engineers requiring the basis of financial accounting for effective water accounting, and for revisiting the mechanism critical to addressing complex problems, integrated multi-level, multi-purpose macro and micro systems at a time when economics itself has been slipping from the main professional interests contained in engineering and accounting.

\section{References}

1. Accounting Professional and Ethical Standards Board (APESB): Compiled APES 110 Code of Ethics for Professional Accountants, APESB, Canberra (2011), http: / / www . apesb. org . au/uploads/july-2012-bm/attachment-5apgs-1-4-47-48-133-135-of-compiled-apes-110-code-of-ethicsfor-professional-accountants-may-2012-marked-up.pdf

2. Boulding, K.E.: Economics and Accounting: The Uncongenial Twins. In: Baxter, W.T., Davisson, S. (eds.) Studies in Accounting Theory, pp. 44-55. Richard D. Irwin, Inc., Illinois (1962)

3. Burritt, R., Hahn, T., Schaltegger, S.: Towards a Comprehensive Framework for Environmental Management Accounting. Links Between Business Actors and Environmental Management Accounting Tools. Australian Accounting Review 12, 39-50 (2002)

4. CSIRO and ABOM: Technical Report, 2007. Climate Change in Australia, CSIRO and The Australian Bureau of Meteorology, Canberra (2007)

5. Graham, W.J.: A Procedure for Estimating Loss of Life Caused by Dam Failure, Office, Report DSO-99-06, United States Dept of Interior, Bureau of Reclamation, Dam Safety, Denver (1999)

6. Guan, D., Hubacek, K.: A New and Integrated Hydro-Economic Accounting and Analytical Framework for Water Resources: A Case Study for North China. Journal of Environmental Management 88(4), 1300-1313 (2008)

7. Lewis, B.: Farm Dams: Planning, Construction and Maintenance. Land Links Press, Victoria (2002)

8. Ngwakwe, C.C.: Rethinking the Accounting Stance on Sustainable Development. Sustainable Development 20, 28-41 (2012)

9. Karlsson-Vinkhuyzen, S.I., Jollands, N., Staudt, L.: Global Governance for Sustainable Energy: The Contribution of a Global Public Goods Approach. Ecological Economics 83, $11-18$ (2012)

10. Kingsford, R.T.: Ecological Impacts of Dams, Water Diversions and River Management on Floodplain Wetlands in Australia. Austral Ecology 25, 109-127 (2000) 
11. Pisaniello, J.D.: Attitudes and Policy Responses to Australian Farm Dam Safety Threats: Comparative Lessons for Water Resources Managers. International Journal of Water Resources Development 26(3), 381-402 (2010)

12. Pisaniello, J.D., Burritt, R.L., Tingey-Holyoak, J.: Dam Safety Management for Sustainable Farming Businesses and Catchments. Agricultural Water Management 98, 507-515 (2011)

13. Pisaniello, J.D., Tingey-Holyoak, J., Burritt, R.L.: Appropriate Small Dam Management for Minimising Catchment-wide Safety Threats: International Benchmarked Guidelines and Demonstrative Cases Studies from Australia. Water Resources Research 48 (2012)

14. Pisaniello, J.D., Tingey-Holyoak, J., Burritt, R.L.: Dual-Extreme Cumulative Impacts and Threats In Agricultural Catchments: The Need for Effective Integrated Policy. Agricultural Water Management 118, 103-112 (2013)

15. Schreider, S.Y., Jakeman, A.J., Letcher, R.A., Nathan, R.J., Neal, B.P., Beavis, S.G.: Detecting Changes in Streamflow Response to Changes in Non-Climatic Catchment Conditions: Farm Dam Development in the Murray-Darling Basin, Australia. Journal of Hydrology 262(1-4), 84-98 (2002)

16. Thanh Nien News: Central flood exacerbated by dam failure. Thanh Nien News (May 10, 2010), http: / / www. thanhniennews. com/2010/Pages/20101005103915. aspx (viewed November 21, 2012)

17. Tingey-Holyoak, J., Burritt, R.: Transdisciplinary Nature of Accounting: A Pathway Towards the Sustainable Future of the Profession. In: Evans, E., Burritt, R., Guthrie, J. (eds.) Emerging Pathways for the Next Generation of Accountants Institute of Chartered Accountants in Australia and Centre for Accounting Governance and Sustainability, Sydney and Adelaide (2012)

18. UN IPCC: Summary for policy makers. In: Qin, S.D., Manning, M., Chen, Z., Marquis, M., Avery, K.B., Tignor, M., Miller, H. L. (eds.), Climate Change 2007: The Physical Science Basis. Contribution of Working Group 1 to the Fourth Assessment Report of the United Nations Intergovernmental Panel on Climate Change. Solomon. Cambridge University Press, Cambridge (2007)

19. Water Accounting Standards Board (WASB): Australian Water Accounting Standard 1, WASB, Canberra (2012),

http://www. bom.gov.au/water/standards/wasb/wasbawas.shtml

20. Yi, S., Dai, Q.: The World's Most Catastrophic Dam Failures: The Collapse Of The Banqiao And Shimantan Dams. In: Thibodeau, J.G., Williams, P.B. (eds.) The River Dragon Has Come! The Three Gorges Dam and the Fate of China's Yangtze River and Its People, ch. 3. M. E. Sharpe, Armonk (1998)

21. Yu, S.C.L.: Microaccounting and Macroaccounting. The Accounting Review 41(1), 8-20 (1966)

22. De Bruijne, M., Van Eeten, M.: Systems That Should Have Failed: Critical Infrastructure Protection in an Institutionally Fragmented Environment. Journal of Contingencies and Crisis Management 15(1), 18-29 (2007)

23. IEAust: Australian Rainfall and Runoff - A Guide to Flood Estimation, 1 \& 2. Institution of Engineers, Australia, Barton, ACT (1999)

24. Pisaniello, J.D., McKay, J.: A Tool to Aid Emergency Managers and Communities in Appraising Private Dam Safety and Policy. Journal of Disaster Studies, Policy and Management 31(2), 176-200 (2007)

25. Tingey-Holyoak, J., Pisaniello, J.D., Linnenluecke, M.: Resilience Policy for Flood Risk Transferred from Private to Public Dams: Insurance and Accounting Issues. Journal of the Asia-Pacific Centre for Environmental Accountability 18(4), 222-250 (2012) 